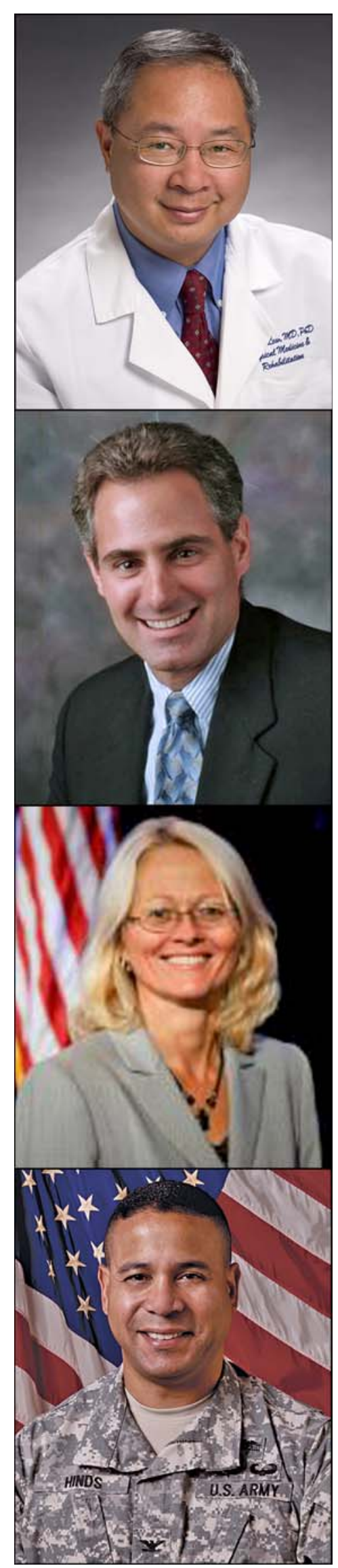

Henry L. Lew, MD, PhD; David X. Cifu, MD; Tamara Crowder, PhD; COL Sidney R. Hinds, MD

\section{National prevalence of traumatic brain injury, posttraumatic stress disorder, and pain diagnoses in OIF/OEF/OND Veterans from 2009 to 2011}

Improvements in protective body armor technology in the past decade, combined with advances in emergency and intensive care medicine, have saved countless lives from battlefield injury [1-4]. Survivors of military conflicts often present with a constellation of injuries, recently described as "polytrauma" by the Veterans Health Administration (VHA) [5]. While traumatic brain injury (TBI) has been coined as the "signature injury" in this generation of combat returnees, other concomitant physical and psychological impairments also require long-term follow-up and care [6-8].

The 2009 study by Lew et al. systematically reviewed 340 Operation Iraqi Freedom (OIF)/Operation Enduring Freedom (OEF) Veterans seen at a VHA Polytrauma Network Site (PNS) from 2007 to 2008, and the data revealed that TBI, posttraumatic stress disorder (PTSD), and pain were reported in 66.8, 68.2, and 81.5 percent of Veterans, respectively [9]. Since these three conditions (TBI, PTSD, and pain) tend to occur in combination (42.1\%), as opposed to existing in isolation (5.3\%, $2.9 \%$, and $10.3 \%$, respectively), their co-occurrence has been referred as the "polytrauma clinical triad" [9]. Given its complexity, an interdisciplinary team approach to diagnosis and treatment has been recommended for patients with this clinical triad [9-10]. Note, however, that this previous study [9] involved only those OIF/OEF Veterans who had (1) sought care within the VHA healthcare system, (2) completed the TBI screening questionnaire at the VHA, (3) answered yes to all four screening questions, (4) agreed to undergo further evaluation, and (5) then completed a comprehensive evaluation at a local VHA PNS (Figure).

This issue of the Journal of Rehabilitation Research and Development includes a landmark article that truly defines the national prevalence of TBI, PTSD, and pain in Veterans from the OIF/OEF/Operation New Dawn (OND) conflicts, encompassing data from 2009 to 2011. Specifically, Cifu et al. [11] conducted a comprehensive investigation that systematically collected and analyzed data from 613,391Veterans who received any healthcare in the VHA from the beginning of 2009 to the end of 2011. Utilizing data from the entire population of OIF/OEF/OND Veterans seen for this three year period, Cifu et al.'s study revealed the actual prevalence of TBI, PTSD, and pain in this new generation of Veterans. Data from 613,391Veterans were captured at the initial stage of entry into the system, when they sought care with the VHA as either outpatients or inpatients, and then at subsequent visits during that three year period. Pooled data from all three years (2009-2011) revealed that only 6.0 percent of this population had the full polytrauma triad expression (TBI, PTSD, and pain). This current percentage (6.0\%) is low when compared with the 42.1 percent from Lew et al.'s previous study [9], which was from a more selective sample since it assessed the local prevalence of the polytrauma triad in Veterans who had not only sought care with the VHA but also completed the TBI screening questionnaire at the VHA, answered yes to all four screening questions, agreed to undergo further evaluation, and completed a comprehensive evaluation at a VHA PNS. Comparisons of the overall and isolated occurrence rates of TBI, PTSD, and pain 
(1) Veterans Seeking Care in VHA Healthcare System

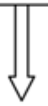

(3) Answered Yes to All Four Screening Questions Pertinent to TBI

(5) Showed Up for Appointment and Then Completed Comprehensive Evaluation at VHA Polytrauma Clinic

Figure.

Flowchart showing sequence of events leading to completion of comprehensive traumatic brain injury evaluation at Veterans Health Administration (VHA) polytrauma clinic. $\mathrm{TBI}=$ traumatic brain injury.

between the two studies are summarized in Tables 1 and 2 , respectively. The drastic contrast in the TBI rates between the two studies was likely because the sample evaluated in the former study had already screened positive for TBI but not for PTSD or pain.

Moreover, Cifu et al.'s results also revealed that "Among those with a TBI diagnosis, the majority also had a mental health disorder, with approximately half having both PTSD and pain. While the absolute number of Veterans increased by over 40 percent from 2009 to 2011, the proportion of Veterans diagnosed with TBI and the high rate of comorbid PTSD and pain in this population has remained relatively stable" [11]. This statement highlights the importance of continued collaborations between the Department of Defense, the VHA, and the Defense and Veterans Brain Injury Center (DVBIC), as well as the fruitful partnerships developed between these Federal entities and academic and private rehabilitation facilities, in order to provide the best care to our wounded warriors and Veterans with polytrauma.
Table 1.

Comparison of overall occurrence rates of traumatic brain injury (TBI), posttraumatic stress disorder (PTSD), and pain.

\begin{tabular}{lrcc}
\hline \multirow{2}{*}{ Study } & \multicolumn{3}{c}{ Overall Occurrence Rate (\%) } \\
\cline { 2 - 4 } & TBI & PTSD & Pain \\
\hline Lew et al. (2009) [9] & 66.8 & 68.2 & 81.5 \\
Cifu et al. (2013) [11] & 9.6 & 29.4 & 40.2 \\
\hline \hline
\end{tabular}

Table 2.

Comparison of isolated occurrence rates of traumatic brain injury (TBI), posttraumatic stress disorder (PTSD), and pain.

\begin{tabular}{lccc}
\hline \multirow{2}{*}{ Study } & \multicolumn{3}{c}{ Isolated Occurrence Rate (\%) } \\
\cline { 2 - 4 } & TBI & PTSD & Pain \\
\hline Lew et al. (2009) [9] & 5.3 & 2.9 & 10.3 \\
Cifu et al. (2013) [11] & 0.8 & 9.5 & 20.1 \\
\hline \hline
\end{tabular}

Henry L. Lew, MD, PhD; ${ }^{1-3^{*}}$ David X. Cifu, MD; ${ }^{3-4}$ Tamara Crowder, PhD; ${ }^{5}$ COL Sidney R. Hinds, $M^{5}$

${ }^{1}$ Department of Communication Sciences and Disorders, John A. Burns School of Medicine, University of Hawai'i at Mānoa, Honolulu, HI; ${ }^{2}$ DVBIC, Richmond, VA; ${ }^{3}$ Department of Physical Medicine and Rehabilitation, Virginia Commonwealth University, Richmond, VA; ${ }^{4}$ Hunter Holmes McGuire Department of Veterans Affairs (VA) Medical Center, Richmond, VA; and VA Physical Medicine and Rehabilitation Program Office, Washington, DC; ${ }^{5}$ DVBIC, Washington, DC

*Email: henrylew@hawaii.edu

\section{REFERENCES}

1. Lew HL. Rehabilitation needs of an increasing population of patients: Traumatic brain injury, polytrauma, and blastrelated injuries. J Rehabil Res Dev. 2005;42(4):xiii-xvi. [PMID:16320135] http://dx.doi.org/10.1682/JRRD.2005.01.0124

2. Lew HL, Poole JH, Vanderploeg RD, Goodrich GL, Dekelboum S, Guillory SB, Sigford B, Cifu DX. Program development and defining characteristics of returning military in a VA Polytrauma Network Site. J Rehabil Res Dev. 2007; 44(7):1027-34. [PMID:18075959] http://dx.doi.org/10.1682/JRRD.2007.05.0073

3. Lew HL, Cifu DX, Crowder AT, Grimes JB. Guest editorial: Sensory and communication disorders in traumatic brain injury. J Rehabil Res Dev. 2012;49(7):vii-x. [PMID:23341287] http://dx.doi.org/10.1682/JRRD.2012.07.0126 
4. Warden D. Military TBI during the Iraq and Afghanistan wars. J Head Trauma Rehabil. 2006;21(5):398-402. [PMID:16983225] http://dx.doi.org/10.1097/00001199-200609000-00004

5. Veterans Health Administration. VHA Handbook 1172.1: Polytrauma rehabilitation procedures. Washington (DC): Department of Veterans Affairs; 2005 Sep 22.

6. Independent Review Group on Rehabilitative Care and Administrative Processes at Walter Reed Army Medical Center and National Naval Medical Center. Rebuilding the trust: Report on rehabilitative care and administrative processes at Walter Reed Army Medical Center and National Naval Medical Center. Arlington (VA): Independent Review Group; 2007.

7. Lew HL, Poole JH, Alvarez S, Moore W. Soldiers with occult traumatic brain injury. Am J Phys Med Rehabil. 2005;84(6):393-98. [PMID:15905652] http://dx.doi.org/10.1097/01.phm.0000163703.91647.a7

8. Lew HL, Poole JH, Guillory SB, Salerno RM, Leskin G, Sigford B. Persistent problems after traumatic brain injury: The need for long-term follow-up and coordinated care. J Rehabil Res Dev. 2006;43(2):vii-x. [PMID:16847779] http://dx.doi.org/10.1682/JRRD.2006.05.0054

9. Lew HL, Otis JD, Tun C, Kerns RD, Clark ME, Cifu DX. Prevalence of chronic pain, posttraumatic stress disorder, and persistent postconcussive symptoms in OIF/OEF veterans: Polytrauma clinical triad. J Rehabil Res Dev. 2009; 46(6):697-702. [PMID:20104399]

http://dx.doi.org/10.1682/JRRD.2009.01.0006

10. Lew HL, Cifu DX, Sigford B, Scott S, Sayer N, Jaffee MS. Team approach to diagnosis and management of traumatic brain injury and its comorbidities. J Rehabil Res Dev. 2007; 44(7):vii-xi. [PMID:18075945]

11. Cifu DX, Taylor BC, Carne WF, Bidelspach D, Sayer NA, Scholten J, Campbell EH. Traumatic brain injury, posttraumatic stress disorder, and pain diagnoses in $\mathrm{OIF} / \mathrm{OEF} /$ OND Veterans. J Rehabil Res Dev. 2013;50(9):1169-76.

This article and any supplementary material should be cited as follows:

Lew HL, Cifu DX, Crowder T, Hinds SR. National prevalence of traumatic brain injury, posttraumatic stress disorder, and pain diagnoses in OIF/OEF/OND Veterans from 2009 to 2011. J Rehabil Res Dev. 2013;50(9):xi-xiv. http://dx.doi.org/10.1682/JRRD.2013.09.0212

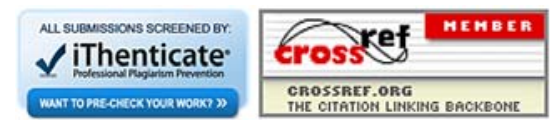


